\title{
DIGNIDADE HUMANA E COMBATE AO RACISMO AMBIENTAL: ACORDO REGIONAL DE ESCAZÚ E PROGRAMA E-CARROCEIROS, EM FORTALEZA, CEARÁ
}

\author{
HUMAN DIGNITY AND THE FIGHT AGAINST ENVIROMENTAL RACISM: REGIONAL AGREEMENT \\ OF ESCAZÚ AND E-CARROCEIROS PROGRAM, IN FORTALEZA, CEARÁ
}

\author{
Gina Vidal Marcílio Pompeu ${ }^{1}$ \\ Liane Maria Santiago Cavalcante Araújo ${ }^{2}$
}

\begin{abstract}
Resumo: Por meio deste artigo, propõe-se a análise do surgimento do racismo ambiental na sociedade de riscos globais, como impacto negativo da globalização, nos países periféricos. Destaca-se a busca pelo aumento da qualidade de vida por parte de uma minoria privilegiada, em detrimento do bem-estar de pessoas e grupos em estado de vulnerabilidade. No contexto da América Latina e do Caribe, são relatados os avanços obtidos em sede de direitos humanos com o Acordo de Escazú, em prol da efetivação da justiça ambiental e da democratização das relações ambientais, sob o enfoque das capacidades de Amartya Sen e Martha Nussbaum. Já na esfera local, é abordado o Programa E-carroceiros, como modelo de integração entre Estado, tecnologia social, iniciativa privada e terceiro setor em Fortaleza, Ceará, e questiona-se a capacidade do programa em promover a igualdade de dignidade e a inclusão social. Nesse viés, conclui-se que a iniciativa favorece a inclusão social dos carroceiros, porém não indica a efetiva igualdade de dignidade, em virtude da natureza da atividade realizada. Trata-se de pesquisa qualitativa, pura, bibliográfica, doutrinária, legislativa e documental.
\end{abstract}

Palavras-chave: Dignidade humana e o combate ao racismo ambiental. Acordo de Escazú. Programa E-Carroceiros.

\begin{abstract}
Through this article, the emergence of environmental racism in the society of global risks is analysed, as a negative impact of globalization, in the peripheral countries. While a privileged minority demands and obtains a higher quality of life, the well-being of vulnerable individuals and groups is directly affected. For this reason, the Latin America and the Caribbean aim to promote human rights by means of the Escazú Agreement, focused on achieving environmental justice and the democratization of environmental relations. The argument used relies on capabilities theory, created by Amartya Sen and Martha Nussbaum. From the international to the local sphere, the brazilian E-carroceiros Program is approached as a model of integration between State, social technology, private initiative and third sector in Fortaleza, Ceará. In this scenario, focused on the waste collectors, the program's ability to promote equality of dignity and social inclusion of these subjects is questioned. In this bias, it is concluded that the initiative indeed benefits the social inclusion of the collectors, but does not implement the aimed equality of dignity, due to the nature of the work performed. The research realized is classified as qualitative, pure, bibliographical, doctrinal, legislative and documentary.

Keywords: Human dignity and the fight against enviromental racism. Escazú Agreement. E-Carriers Program.
\end{abstract}

Recebido em 10 de janeiro de 2019 Avaliado em 8 de abril de 2020 (AVALIADOR A) Avaliado em 27 de abril de 2020 (AVALIADOR B)

Aceito em 27 de abril de 2020

\footnotetext{
1 Doutora em Direito pela Universidade Federal de Pernambuco; Professora na Pós-graduação Stricto Sensu, (Mestrado e Doutorado) em Direito da Universidade de Fortaleza; Avenida Washington Soares, 1321, Edson Queiroz, 60811-905, Fortaleza, Ceará, Brasil; https://orcid.org/0000-0003-0446-7452; ginapompeu@unifor.br

2 Mestra em Direito Constitucional pela Universidade de Fortalez; Bolsista Capes/Brasil - Pesquisadora dos Grupos REPJAL e GEPEDI, ambos da Universidade de Fortaleza; https://orcid.org/0000-0003-3428-522X; lianemariaadv@gmail.com
} 


\section{Introdução}

Nas últimas décadas, o movimento social de defesa ao meio ambiente tem promovido o diálogo com outras questões democráticas em prol da implantação de uma sociedade participativa e cidadã, no que se refere à definição de políticas socioambientais. Para tanto, é necessário efetivar os princípios democráticos nas relações sociais, com o propósito de promover a democratização do controle e utilização dos recursos naturais.

Em meio a esse cenário, há uma preocupação com a distribuição dos efeitos prejudiciais provenientes da manutenção de padrões de vida de elevada entropia, entre os quais se situa a crise ambiental, vivenciada como resultado da globalização que domina o planeta desde a segunda metade do século XX. Nessa perspectiva, propõe-se análise do fenômeno racismo ambiental como um impacto negativo da globalização, especialmente nos países periféricos, cujas populações encontram-se em permanente estado de exceção.

Nesse contexto, destacam-se os processos de globalização hegemônica ditados pelos detentores do capital financeiro, com dimensões mundiais, aptos a influenciar o ser humano, independentemente de onde ele se situe. Nessa medida, vislumbra-se, de um lado, a procura incessante pelo aumento de qualidade de vida e do lucro por uma minoria privilegiada e, de outro, a submissão de pessoas e grupos a circunstâncias econômicas, sociais e ambientais vulneráveis. É neste cenário complexo e multifacetado, identificado pela convivência de interesses antagônicos que se propõe o debate acerca do racismo ambiental. Constata-se que os grupos hegemônicos criam e impõem linguagens, ideologias e crenças alinhadas com a rejeição e marginalização de ideias contrapostas.

Para tanto, é estudado inicialmente o Acordo de Escazú, no âmbito da Comissão Econômica para a América Latina e o Caribe (CEPAL) das Nações Unidas, importante instrumento jurídico internacional que se refere aos direitos de acesso (à informação ambiental; à participação pública nos processos de tomada de decisões relacionados a questões ambientais; e à justiça em questões ambientais). Esses direitos humanos encontram-se fundamentados no Princípio 10 da Declaração do Rio de Janeiro sobre o Meio Ambiente e o Desenvolvimento, assinada na Conferência Rio-92. Na sequência, investiga-se o surgimento do racismo ambiental, sua origem no tempo e no espaço. Por fim, propõe-se uma análise do Programa E-carroceiros, desenvolvido no Brasil, em Fortaleza, Ceará.

Desta feita, parte-se do contexto internacional para a esfera local, com vistas a avaliar se a política pública brasileira em questão (resultado da interação entre Estado, terceiro setor, iniciativa privada, sociedade beneficiária e tecnologia) constitui um exemplo de combate ao racismo ambiental mediante a aplicação prática do Acordo de Escazú na cidade de Fortaleza, Ceará, Brasil. Para tanto, investiga-se a capacidade do Programa E-carroceiros em promover a igualdade de dignidade e a inclusão social dos carroceiros cadastrados. Trata-se de pesquisa pura, de abordagem qualitativa, bibliográfica e documental, voltada, no campo téorico, para o estudo de doutrina jurídica nacional e internacional. Foram utilizados artigos científicos de outras áreas do conhecimento, com recorte 
feito a partir das expressões: catadores, carroceiros, saúde, lixo, trabalho, ambiente. $\bigcirc$ método utilizado foi o hipotético-dedutivo.

\section{Acordo Regional de Escazú: justiça ambiental e igualdade de capacidades no século XXI}

Nas últimas décadas do século XX, a questão ambiental ganha contornos de problema global que mobiliza sociedade organizada, meios de comunicação e governos dos países do mundo (RABELO, 2010). É a partir da difusão das preocupações de movimentos e governos que se origina o Acordo Regional sobre Acesso à Informação, Participação Pública e Acesso à Justiça em Assuntos Ambientais na América Latina e no Caribe (Acordo de Escazú). O documento, que resulta de debates entre 24 países da América Latina e do Caribe, teve sua negociação concluída em 3 de março de 2018, em São José, na Costa Rica (BRASIL, 2018), e foi adotado em Escazú, no mesmo país, em 4 de marco do mesmo ano (ORGANIZAÇÃO DAS NAÇÕES UNIDAS, 2018).

Trata-se do primeiro Acordo Regional vinculante para a proteção dos "direitos de acesso" em assuntos ambientais (COMISSÃO ECONÔMICA PARA A AMÉRICA LATINA E O CARIBE, 2018b), classificados em direito de acesso à informação ambiental, direito à participação pública nos processos de tomada de decisões relacionados a questões ambientais e direito de acesso à justiça em questões ambientais (COMISSÃO ECONÔMICA PARA A AMÉRICA LATINA E O CARIBE, 2018b). Sua importância remete ao fato de que conflitos ambientais geralmente envolvem disputas por uma mesma base material da atividade ou até por bases distintas, porém relacionadas com os mesmos ecossistemas, mediadas pela atmosfera, florestas, solo, rios, dentre outros (RABELO, 2010).

O Acordo em questão decorre do Princípio 10 da Declaração do Rio de Janeiro sobre o Meio Ambiente e o Desenvolvimento (COMISSÃO ECONÔMICA PARA A AMÉRICA LATINA E O CARIBE, 2018a), assinada na Conferência Rio-92, que dispõe exatamente sobre os direitos de acesso à informação, participação pública e acesso à justiça em assuntos ambientais. A questão foi discutida também na Conferência Rio+20, em 2012, com foco no estabelecimento de padrão mínimo de aplicação desse Princípio na região latino-americana e caribenha. Nesse mesmo ano, tem início o processo de negociação do Acordo Regional de Escazú, no âmbito da Comissão Econômica para a América Latina e o Caribe (COMISSÃO ECONÔMICA PARA A AMÉRICA LATINA E O CARIBE, 2020).

Os debates ocorreram durante nove rodadas, realizadas em diferentes países, inclusive no Brasil (em Brasília), em março de 2017. Segundo o Ministério das Relações Exteriores, a assinatura brasileira reafirma o compromisso histórico do país com o multilateralismo e o desenvolvimento sustentável. Com efeito, "O Brasil participou ativamente dos trabalhos que concluíram o Acordo de Escazú e manteve amplo exercício de consultas com representantes de governo, da sociedade e da academia, para a construção das posições nacionais." (BRASIL, 2018). 
De outro giro, o documento foi elogiado pelo ex-Presidente costarriquenho, Luis Guillermo Solís, que destacou a importância jurídica do acordo e da "democracia ambiental", termo legal que determina a participação de todos no processo de preservação do ambiente (COMISSÃO ECONÔMICA PARA A AMÉRICA LATINA E O CARIBE, 2018b). No Prólogo do Acordo, resta consignada especial atenção para pessoas e grupos em situação de vulnerabilidade.

Acima de tudo, este tratado tem por objetivo lutar contra a desigualdade e a discriminação e garantir os direitos de todas as pessoas a um meio ambiente saudável e ao desenvolvimento sustentável, dedicando especial atenção às pessoas e grupos em situação de vulnerabilidade e colocando a igualdade no centro do desenvolvimento sustentável. (COMISSÃO ECONÔMICA PARA A AMÉRICA LATINA E O CARIBE, 2018b).

A expressão "pessoas ou grupos em situação de vulnerabilidade" é definida, no documento, como aqueles que encontram especiais dificuldades para exercer com plenitude os direitos de acesso, diante de circunstâncias ou condições inerentes ao contexto nacional de cada Parte, nos termos do artigo 2, letras "a" e "e", do Acordo de Escazú (COMISSÃO ECONÔMICA PARA A AMÉRICA LATINA E O CARIBE, 2018b). De fato, as ameaças não se apresentam igualmente distribuídas entre as populações humanas, pois as gerações fragilizadas das civilizações humanas encontram-se mais expostas aos efeitos do risco globalizado, apesar de fatores culturais que permitem, em tese, a adaptação diferenciada a problemas e desafios novos (PEREIRA; BROUWERS, 2011).

Destarte, o Acordo de Escazú legitima o direito humano ao meio ambiente saudável, ao desenvolvimento sustentável e à igualdade no centro do desenvolvimento sustentável (COMISSÃO ECONÔMICA PARA A AMÉRICA LATINA E O CARIBE, 2018b). Para tanto, esclarece no seu artigo $1^{\circ}$ que objetiva garantir

[...] a implementação plena e efetiva, na América Latina e no Caribe, dos direitos de acesso à informação ambiental, participação pública nos processos de tomada de decisões ambientais e acesso à justiça em questões ambientais, bem como a criação e o fortalecimento das capacidades e cooperação, contribuindo para a proteção do direito de cada pessoa, das gerações presentes e futuras, a viver em um meio ambiente saudável e a um desenvolvimento sustentável.

Segundo a classificação de Bosselmann (2015), o Acordo não constitui instrumento de governança para a sustentabilidade porque concentra-se no ser humano, e não em toda a comunidade (todas as formas de vida), dentro do viés ecológico. Por essas características, deve ser classificado como documento de governança ambiental, que concebe a figura do sujeito de direito intergeracional no processo de ordenamento e planejamento urbano ambiental.

De outro giro, o art. $1^{\circ}$ do Acordo faz referência ao enfoque das capacidades, como forma de contribuir para a proteção do direito de cada ser humano a viver em meio ambiente saudável e ao desenvolvimento sustentável (COMISSÃO ECONÔMICA PARA A AMÉRICA LATINA E O 
CARIBE, 2018b). Trata-se de teoria desenvolvida por Amartya Sen (2000), que desloca o foco dos problemas sociais: da análise da pobreza para a privação de capacidades básicas, apreciadas com base nos funcionamentos reais das pessoas (longevidade, condição de saúde, alfabetização, etc.); e Martha Nussbaum, para quem as capacidades abrangem tanto direitos de primeira geração (liberdades políticas e civis) quanto de segunda geração (econômicos e sociais). Esses, assim como "[...] os direitos humanos oferecem um conjunto moral e humanamente rico de objetivos para o desenvolvimento, no lugar da 'riqueza e pobreza dos economistas' [...]" (NUSSBAUM, 2013, p. 351).

Já o artigo 10, em seu item 1, informa que, como forma de contribuir para a efetivação do Acordo de Escazú, as Partes assumem o compromisso de criar e fortalecer as capacidades nacionais, a partir de suas prioridades e necessidades (COMISSÃO ECONÔMICA PARA A AMÉRICA LATINA E O CARIBE, 2018b). A lista das capacidades está fundamentada na definição de vida em consonância com a dignidade da pessoa humana, que corresponde à "[...] necessidade de um ser materialmente necessitado", segundo Nussbaum (2013, p. 343). A autora compreende as capacidades básicas dos seres humanos como as "[...] fontes de exigências morais onde quer que as encontremos: elas exercem uma exigência moral de que devem se desenvolver e de que se lhes deve ser fornecida uma vida realizadora e não atrofiada." (NUSSBAUM, 2013, p. 343-344).

Diante dessa constatação, a organização da vida em comum deve respeitar os três dados centrais da inteligência moral: dignidade do ser humano enquanto ser ético; sociabilidade humana; caráter múltiplo das necessidades humanas. Nessa medida, o Estado deve se responsabilizar, na esfera do direito interno, por um nível limítrofe mínimo a ser satisfeito, no que diz respeito à efetivação dos direitos humanos (NUSSBAUM, 2013).

Nessa perspectiva, todos os homens e mulheres têm direito a patamar mínimo de cada um dos bens centrais contidos na lista das capacidades. Da mesma forma, todos têm o dever de encontrar forma de viver e de cooperar que propicie aos seres humanos vida digna. "A educação é a chave para todas as capacidades. [...] Nada é mais importante do que isso para a democracia, para a satisfação da vida, para a igualdade e mobilidade dentro da própria nação, para a política efetiva para além das fronteiras nacionais." (NUSSBAUM, 2013, p. 396-397).

Nessa ordem de raciocínio, é forçoso reiterar que o objetivo maior da educação deve ser a inclusão, estímulo e respeito à interatividade do outro e nada disso se alcança violando ou ignorando sua realidade. Aceitar o multiculturalismo e respeitar as necessidades, prestigiando o saber local, sem reducionismos populistas, é tarefa que requer coragem e preparo adequado, porquanto infinitamente desafiadora. (SILVA; HAHN; TRAMONTINA; 2011, p. 219-220).

Destarte, a opção pelo enfoque das capacidades alinha-se com o propósito de educar para garantir igualdade de dignidade, tanto no cenário jurídico nacional quanto internacional (NUSSBAUM, 2013). Trata-se de abordagem fundada em modelo de educação universal que permite aliar a prática aos saberes locais, de modo a promover efetivamente a inclusão. Com isso, propõe- 
se a superar a homogeneização de tratamentos e conteúdos que findam por limitar o homem a determinada realidade, diferente da sua.

A universalidade é da prestação do direito social subjetivo à educação, os sujeitos educandos desse processo são, como salienta Geertz, essencialmente iguais em sua natureza, mas transversalmente individualizados por suas perspectivas locais, que merecem e devem ser consideradas pela arte e pelo dever jurídico de educar. (SILVA; HAHN; TRAMONTINA; 2011, p. 220).

Nessa linha, o incentivo à educação, com respaldo legal, conduz ao progresso. Isto porque "Homens livres, aptos ao desenvolvimento de suas potencialidades, são ao mesmo tempo possuidores de razão, reconhecem a necessidade de viver em sociedade, sob as leis de um Estado e de preservar os meios de sobrevivência e de buscar o desenvolvimento humano." (POMPEU; NÉRI, 2012, p. 7).

Sen (2000) destaca que os aspectos causais que motivam algumas privações funcionais vão além da privação de renda, o que torna difícil a tarefa de ajustá-los, por motivos puramente táticos. A seu turno, Nussbaum (2013, p. 351) afirma que "Incapacidades físicas, velhice, características típicas de cada sexo e fatores afins são fontes particularmente sérias de deficiências de capacidades por estarem fora do controle das pessoas afetadas."

Isso também se observa com o fenômeno do racismo ambiental, modalidade de injustiça ambiental que só pode ser combatida por meio da efetivação da "igualdade de dignidade" nas esferas econômica, social e ambiental, a partir de distribuição de bens básicos que não deixe de observar o imperativo pautado na necessidade de igual respeito por todos (NUSSBAUM, 2013).

É nessa linha que o Acordo de Escazú preconiza, em seu artigo 4, nos itens 2, 3, 4, 5 e 9 , os deveres mínimos a serem observados pelos Estados-nações (Partes). São eles: dever de assegurar a liberdade de exercício dos direitos enumerados no documento; dever de agir de ofício, no direito interno, para garantir a implementação do Acordo Regional, através de medidas legislativas, regulamentares, administrativas, etc.; dever de informação, para facilitar o aprendizado acerca dos direitos de acesso; dever de orientação e assistência ao público, com atenção especial para pessoas ou grupos em situação de vulnerabilidade; dever de promover o uso das novas tecnologias da informação e comunicação, sem que os meios eletrônicos sejam utilizados de modo a promover restrições ou discriminações para o público (COMISSÃO ECONÔMICA PARA A AMÉRICA LATINA E O CARIBE, 2018b).

O documento enumera ainda, no artigo 4, itens 1 e 6, o dever das Partes de garantir ao homem o direito a viver em meio ambiente saudável; qualquer outro direito humano universalmente reconhecido, que guarde relação com o Acordo de Escazú; e ambiente propício para o trabalho das pessoas, associações, organizações e grupos que promovam a proteção do meio ambiente, além de reconhecimento e proteção. No campo das faculdades, nos itens 8 e 10 do mesmo artigo, preconizase que cada Parte buscará adotar a interpretação mais favorável ao pleno gozo e respeito dos direitos de acesso; e que as nações poderão promover o conhecimento do conteúdo em outros fóruns 
internacionais relacionados à temática do meio ambiente (COMISSÃO ECONÔMICA PARA A AMÉRICA LATINA E O CARIBE, 2018b).

$\mathrm{Da}$ análise do Acordo, verifica-se, simultaneamente, o estabelecimento de deveres e faculdades aos Estados-nações, com foco na efetivação dos direitos de acesso, na perspectiva ambiental. $O$ instrumento encontra-se sujeito à ratificação, aceitação ou aprovação dos 22 Estados que o assinaram (dentre as 33 nações da América Latina e do Caribe), e permanecerá disponível para assinatura, pelos demais, na Sede da ONU - em Nova York, até 26 de setembro de 2020 (COMISSÃO ECONÔMICA PARA A AMÉRICA LATINA E O CARIBE, 2018b).

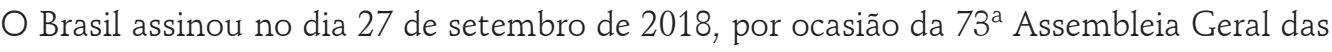
Nações Unidas, realizada na sede das Nações Unidas, em Nova York (BRASIL, 2018), porém ainda não ratificou. Nesse momento, o Acordo encontra-se ratificado por apenas oito países: Antígua e Barbuda; Bolívia; Guiana; Nicarágua; Panamá; São Vicente e Granadinas; São Cristóvão e Nevis e Uruguai. A última ratificação foi do Panamá, que se deu no dia 10 de março de 2020 (COMISSÃO ECONÔMICA PARA A AMÉRICA LATINA E O CARIBE, 2020).

Em suma, o Acordo de Escazú objetiva introduzir princípios democráticos nas relações sociais que são mediadas pela natureza. Além disso, evidencia a busca da América Latina e do Caribe pela democratização do controle e utilização dos recursos naturais (RABELO, 2010) diante da sociedade de riscos globais, que lhes retira sua margem de manobra e promove crescentes ameaças à unidade nacional (BERCOVICI, 2006).

Destarte, constitui documento essencial ao combate dos impactos negativos provocados pelos processos de globalização, que introduzem nova racionalidade na estrutura geopolítica mundial. A complexidade dos conflitos envolve grupos sociais, Estados e interesses hegemônicos, de um lado; e grupos sociais, Estados e interesses subalternos, de outro (PEREIRA; BROUWERS, 2011). Para os países periféricos, o risco reside na limitação da democracia ao mecanismo eleitoral, estritamente formal (BERCOVICI, 2006).

Daí a relevância do documento para o debate voltado para o racismo ambiental e a destinação de resíduos sólidos (lixo) na era da complexidade. O Acordo Regional de Escazú é o resultado da articulação do movimento social de defesa ao meio ambiente com as lutas democráticas nas últimas décadas, em prol da implantação de sociedade marcada pela participação e cidadania na definição de políticas socioambientais (RABELO, 2010).

É importante ressalvar, conforme alerta o Ministério das Relações Exteriores, que a vigência do Acordo somente terá início no nonagésimo dia a contar da data do depósito do décimo primeiro instrumento de ratificação, aceitação, aprovação ou adesão pelo país (BRASIL, 2018). Todavia, já é possível observar a aplicação prática das linhas mestras do referido documento no Programa E-carroceiros, promovido pela Prefeitura de Fortaleza, Ceará, em parceria com o Banco Palmas, a iniciativa privada (ECOFOR) e os próprios carroceiros, conforme restará explicitado no tópico a seguir. 


\section{Sociedade dos riscos globais e surgimento do racismo ambiental}

É possível constatar que as lutas pelo poder econômico ultrapassam as barreiras do cenário estatal político e atingem as esferas social e cultural, em um contexto de interdependência global e intercâmbio de valores. Com isso, findam por impactar os grupos economicamente mais fragilizados, que sofrem discriminações. Nessa medida, é preciso enfrentar a opressão com foco no combate e solução desse problema. Para estabelecer a base sólida dessa medida, há que se planejar e executar ações capazes de minimizar tensões, reprimir a propagação dos racismos e reafirmar os direitos humanos, com destaque para o direito à pluralidade e às diferenças culturais (ANDRIGHETTO; OLSSON, 2014).

Nessa linha, as questões voltadas para o desenvolvimento, a preservação do meio ambiente e a qualidade de vida da população têm se entrelaçado em meio às lutas de movimentos sociais, haja vista os impactos negativos originados pelas atividades econômicas. Entre esses impactos, evidenciados pelos conflitos ambientais no mundo globalizado, figura o racismo ou discriminação ambiental. Trata-se de modalidade de discriminação a certas pessoas ou grupos sociais que se encontram obrigados a suportar os efeitos da distribuição desigual dos riscos ambientais.

É certo que o Estado Democrático de Direito não é capaz de tratar todos de forma exatamente igual, pois cada ser humano e cada grupo social possui peculiaridades e sensibilidades próprias. Contudo, a isonomia deve ser perseguida como critério garantidor de justiça, em prol da inclusão social, consubstanciada na inserção de forma digna na sociedade, na família e também na esfera individual. Isto porque, para aceitar o outro, o homem precisa aceitar-se a si mesmo, o que também envolve relação saudável com o ambiente no qual se encontra inserido.

Parte-se da premissa de que todo ser humano nasce com a pretensão de ser aceito pelo outro, sob pena de rejeição capaz de originar diversos sintomas psicossociais. Aí reside a relevância do ambiente em que se desenvolve. Com efeito, a pessoa que cresce em condições ambientais saudáveis possui mais chances de apresentar hábitos adequados para o bom desenvolvimento, em sua esfera pessoal, social ou mesmo psicossocial. Em contrapartida, as pessoas que crescem em ambientes degradados (como morros, lixões e aterros sanitários), poluídos ou ecologicamente desequilibrados têm mais chance de desenvolver doenças, sintomas psicológicos e até comportamentos sociais incompatíveis, por falta de oportunidades de inserção social.

Pompeu e Sampaio (2017) lembram que carece efetivar patamar mínimo civilizatório de alcance aos direitos sociais, pedra angular da qual nascem os outros direitos. Para a autora, a vigília atual consiste em evitar que o desenvolvimento econômico se limite à especulação financeira e à concentração de renda em detrimento do elemento essencial do Estado: a população.

Nessa perspectiva, a sociedade de riscos globais apresenta problemas e conflitos diferenciados, provenientes do desenvolvimento da crise ecológica, cujos efeitos são ampliados em 
decorrência da exploração tecnológica da biodiversidade (AYALA, 2011). No lugar da distribuição de riqueza, característica da sociedade da escassez, Beck (2011, p. 42) afirma que assume a lógica da distribuição de riscos e esclarece que "[...] sociedades de risco simplesmente não são sociedades de classes", assim como situações de ameaça e conflitos não são reservados exclusivamente a determinada classes.

Destarte, os atores da modernização acabam inevitável e bastante concretamente, entrando na ciranda dos perigos que eles próprios desencadeiam e com os quais lucram. Na perspectiva dos conflitos ambientais, vislumbra-se sempre um problema ambiental correlato; mas a recíproca não é verdadeira. O conceito de problemas ambientais urbanos associa-se ao impacto da urbanização dissociada do planejamento necessário sobre os ecossistemas, que origina a precariedade dos serviços urbanos, em face da omissão do poder público e dos descuidos dos próprios cidadãos. Diferentemente, os conflitos decorrem do efetivo confronto de interesses entre atores sociais diversos quanto à utilização ou gestão do meio ambiente (RABELO, 2010).

Neste diapasão, é necessário que a população adquira a consciência do problema (dano ou risco) assim como o desejo de mudar, a fim de que possa se mobilizar, por meio do conflito ambiental, no sentido de interromper ou eliminar o processo de ameaça. Essa mudança, contudo, deve enfrentar o desafio primeiro de criar instrumentos de análise capazes de interpretar a complexidade dos processos sociais, ecológicos e políticos, os quais colocam a natureza no interior dos conflitos (RABELO, 2010).

Entre tais problemas, constata-se a injustiça ambiental, que ocorre quando pessoas ou grupos de qualquer raça, classe ou nível de renda sofrem impactos ambientais negativos de atividades econômicas. Quando se dá em face de populações tradicionais, como indígenas, ribeirinhos, quebradeiras de coco, marisqueiras, caiçaras, agricultores familiares e outras populações étnicas vulnerabilizadas, configura racismo ambiental. Trata-se de forma de discriminação institucionalizada traduzida em ações ou práticas realizadas por sujeitos dos grupos raciais ou étnicos dominantes, que geram impactos discriminatórios e negativos perante membros de grupos étnicos ou raciais subordinados. Rabelo (2010, p. 307) assevera que:

No Brasil, alguns conflitos ambientais são conhecidos: na Amazônia, com a proliferação dos garimpos; nas grandes cidades, envolvendo o Estado; a especulação imobiliária e os movimentos populares relacionados ao direito ao uso e ocupação do solo; a instalação de projetos hidroagrícolas no vale do São Francisco e no polígono das secas (Nordeste), envolvendo as populações locais e o Estado no processo de implantação e execução dos projetos; a transposição do Rio São Francisco; e em vários estados do Brasil, a luta de índios e quilombolas para terem suas terras demarcadas.

Como resultado, vislumbra-se a adoção de critério específico de classificação social como justificativa para a obtenção de privilégios ou de diferenças pertinentes ao acesso a recursos ambientais. Logo, o racismo ambiental constitui espécie de injustiça ambiental (RABELO, 2010) pela 
qual se impõe ao ser humano condição insustentável de vida. Nesse cenário, a população com baixo nível de renda encontra-se privada de desenvolver seus direitos de personalidade e capacidades para inclusão na esfera das oportunidades (SEN, 2000).

Vale lembrar que o movimento de justiça ambiental surgiu entre os negros norte-americanos no final da década de 1970, a partir da articulação de lutas sociais, territoriais e ambientais. O conflito girou em torno das condições inadequadas de saneamento e da contaminação química e disposição de lixo tóxico em comunidades e postos de trabalho. Nesse contexto histórico, sindicatos e organizações de minorias étnicas promovem estudos acerca da distribuição espacial desigual da poluição segundo a raça (RABELO, 2010).

Nessa linha, por volta de 1978, ganha ênfase o combate à localização predominante de lixo tóxico e perigoso em áreas de habitação de população negra de Warren County, na Carolina do Norte, Estados Unidos. Alguns anos depois, em 1982, vem à tona a descoberta da concentração de 3/4 dos aterros de resíduos tóxicos na região sudeste norte americana, em bairros habitados por negros. Diante disso, a população realiza manifestação que resulta na prisão de inúmeras pessoas, o que amplia o debate para além das fronteiras dos Estados Unidos. No Brasil, o racismo ou discriminação ambiental não é muito conhecido pela sociedade, à exceção das Organizações Não Governamentais (ONGs), academia e lideranças de determinados movimentos sociais (RABELO, 2010).

Todavia, a Convenção Internacional sobre a Eliminação de Todas as Formas de Discriminação Racial, aprovada no Brasil pelo Decreto Legislativo n. 23, de 21 de junho de 1967 e promulgada pelo Decreto n. 65.810, de 8 de dezembro de 1969, estabeleceu, desde então, em seu Artigo I, item 1, que discriminação racial é

[...] qualquer distinção, exclusão, restrição ou preferência baseadas em raça, côr, descendência ou origem nacional ou étnica que tem por objetivo ou efeito anular ou restringir o recebimento, gôzo ou exercício num mesmo plano, (em igualdade de condição), de direitos humanos e liberdades fundamentais no domínio político econômico, social, cultural ou em qualquer outro domínio de vida pública. (BRASIL, 1969).

Importa destacar, a partir do conceito apresentado, que o referido documento enumerou obrigações para os Estados Partes, que se comprometem a adotar, sem demora, uma política de eliminação da discriminação racial - em todas as suas formas, o que inclui, portanto, o racismo em sua modalidade ambiental. Assim, os Estados assumem o compromisso de favorecer, quando cabível, organizações e movimento multirraciais, além de outros meios capazes de extinguir as barreiras entre raças e desestimular o que possa reforçar a divisão racial (Artigo II, item 1, alínea "e") (BRASIL, 1969). A Convenção prevê, ainda, em seu Artigo III, que "Os Estados Partes especialmente condenam a segregação racial e o apartheid e comprometem-se a proibir e a eliminar nos territórios sobre sua jurisdição tôdas as práticas dessa natureza." (BRASIL, 1969). 
Nessa mesma linha, merece destaque a Declaração sobre o Direito ao Desenvolvimento, adotada pela Resolução n. 41/128 da Assembleia Geral das Nações Unidas, de 4 de dezembro de 1986. A despeito de não se tratar de documento ratificado pelo Brasil, reforça, em seu artigo $5^{\circ}$, o papel dos Estados na adoção de medidas resolutas com vistas a extinguir violações dos direitos humanos dos povos e dos seres humanos, como todas as formas de racismo e discriminação racial (ORGANIZAÇÃO DAS NAÇÕES UNIDAS, 1986). Em 1993, destacam-se a Declaração e o Programa de Ação de Viena, atos internacionais adotados pela Conferência Mundial sobre Direitos Humanos, entre os dias 14 e 25 de junho, não ratificados pelo Brasil. Em seu artigo 15, preconizam que

[...] A eliminação rápida e abrangente de todas as formas de racismo de discriminação racial, de xenofobia e de intolerância associadas a esses comportamentos deve ser uma tarefa prioritária para a comunidade internacional. Os Governos devem tomar medidas eficazes para preveni-las e combatê-las. Grupos, instituições, organizações intergovernamentais e não governamentais e indivíduos de modo geral devem intensificar seus esforços de cooperação e coordenação de atividades contra esses males. (ORGANIZAÇÃ O DAS NAÇÕ̃ES UNIDAS, 1993).

Ademais, a Conferência Mundial sobre Direitos Humanos reconhece a eliminação do racismo e da discriminação racial como objetivo prioritário da comunidade internacional e programa mundial de promoção no âmbito dos direitos humanos (Artigo 19). Nesse sentido, convoca todos os Governos a providenciarem ações imediatas, individual ou coletivamente, e políticas robustas com o objetivo de evitar e combater todas as formas de racismo, xenofobia ou manifestações análogas de intolerância (Artigo 20 e 24) (ORGANIZAÇÃO DAS NAÇÕES UNIDAS, 1993).

Diante do contexto normativo internacional apresentado, e como forma de combate ao racismo ambiental, merece destaque a lição de Bosselmann, que alerta para a necessidade de construção de "governo pela sustentabilidade". Para tanto, o autor assevera que é preciso pensar as decisões de ordenamento do território a partir da perspectiva de toda a comunidade, o que inclui os interesses coletivos das atuais e futuras gerações de seres humanos e também de outras espécies (BOSSELMANN, 2015).

Nessa medida, há que se reformar o pensamento acerca de governança e do papel das pessoas nela, com a ampliação do foco das relações sociais para as relações ecológicas. A sustentabilidade deve ser reconhecida como o "[...] princípio ético fundamental, com orientação clara para o projeto de lei e governança" (BOSSELMANN, 2015, p. 222). A governança ambiental, consubstanciada, no mais das vezes, em programas nacionais minimalistas, cuja superficialidade promove a manutenção da crise ecológica (no interesse da produtividade e do lucro) deve dar lugar à governança para a sustentabilidade, pautada em avaliação holística, com valores de fundo, do uso racional da terra (BOSSELMANN, 2015).

É certo que os riscos contemporâneos não podem ser comunicados de forma eficiente por meio de índices e padrões de segurança, nem por padrões de probabilidade estatística. Por esse 
motivo, Ayala afirma que o modelo de sociedade existente não chega a ser tipicamente definido e administrado por cientistas, em virtude da emergência dos conflitos existentes (AYALA, 2011). Todavia, é preciso reconhecer que a manutenção do conceito humano de necessidade e conveniência frequentemente empregado nas decisões de planejamento privilegia o ganho pessoal de curto prazo, em detrimento da igualdade social e da segurança humana (BOSSELMANN, 2015).

Decorre daí a relevância de um olhar sensível voltado para a questão ambiental, sem deixar de lado a diversidade sociocultural e os conflitos existentes entre diferentes projetos de apropriação e significação do mundo material. Por esse motivo, ganha destaque, no contexto da América Latina e do Caribe, o Acordo Regional de Escazú, como ferramenta jurídica com potencial para fomentar a construção de quadro analítico capaz de orientar as políticas ambientais em prol da efetividade e da legitimidade democrática (RABELO, 2010).

\section{Acordo Regional de Escazú e o Projeto E-Carroceiros no combate ao racismo ambiental}

O Acordo de Escazú destaca-se por ter adotado a teoria das capacidades, reconhecida por Nussbaum (2013) como teoria internacional de direitos humanos, com foco na democracia ambiental. Com efeito, "[...] não cabe mais perseverar na preferência das normas de direito internacional ou de direito interno porque, hodiernamente, o que se verifica é que o primado da norma deverá ser aquele que melhor venha proteger os direitos humanos [...]" (COSTA; STRAPAZZON, 2014, p. 29).

Diante dessa realidade, cabe ao Direito formular regras de convívio capazes de estabelecer o compartilhamento pacífico das liberdades individuais (POMPEU; NÉRI, 2012) e resguardar os direitos humanos correlatos. No cenário da América Latina e do Caribe, especificamente, verifica-se uma instabilidade econômica ocasionada por fatores externos, além da profunda crise econômica interna. Tratam-se de países periféricos que vivem em constante estado de exceção econômico, marcados pela utilização frequente dos poderes de emergência com vistas a limitar os direitos da população em geral, para garantir a propriedade privada e a acumulação capitalista (BERCOVICI, 2006).

É nessa medida que o fluxo de capital que gira em torno da globalização não alcança áreas mais pobres, carentes de investimentos (PEREIRA; BROUWERS, 2011). Assim, instrumentos jurídicos como o Acordo de Escazú são necessários para que o Direito exerça seu "[...] papel instrumental de fixar o modelo exploratório e os critérios de distribuição." (POMPEU; NÉRI, 2012, p. 6). Cumpre acrescentar, neste ponto, que tais critérios devem abranger a questão da distribuição de dignidade em meio à sociedade de riscos globais.

No campo do saneamento básico e da construção de aterros sanitários, por exemplo, o crescimento populacional registrado na última metade do século $\mathrm{XX}$, sucedido por avanços tecnológicos e aumento do consumo, ocasionou a produção de resíduos sólidos em quantidade e diversidade jamais vistas. Por via de consequência, o tratamento e a disposição adequada de resíduos 
desafiam as autoridades públicas e a própria sociedade a pensar soluções criativas e eficazes, para evitar problemas ambientais e de saúde (SANTOS; SILVA, 2011), especialmente das pessoas ou grupos em estado de vulnerabilidade.

Em 2017, calcula-se que a geração total anual de resíduos sólidos urbanos (RSU) no Brasil alcança 78,4 milhões de toneladas (com aumento de cerca de 1\% em relação ao ano anterior). Destas, somente 71,6 milhões de toneladas foram coletadas, o que demonstra "[...] um índice de cobertura de coleta de 91,2\% para o país", conforme dados da Associação Brasileira de Empresas de Limpeza Pública e Resíduos Especiais (2017, p. 14). Logo, 6,9 milhões de toneladas de resíduos não foram sequer objeto de coleta no país. No mesmo ano, apenas 59,1\% do RSU coletado (cerca de 42,3 milhões de toneladas) foram dispostos em aterros sanitários. O restante (40,9\%) foi direcionado para locais inadequados (aterros controlados e lixões), por 3.352 municípios brasileiros (ASSOCIAÇÃO BRASILEIRA DE EMPRESAS DE LIMPEZA PÚBLICA E RESÍDUOS ESPECIAIS, 2017, p. 19).

Com isso, mais de 29 milhões de toneladas de resíduos seguiram para lixões ou aterros controlados, que não apresentam sistemas e medidas necessárias para a preservação do meio ambiente contra danos e degradações, com danos diretos à saúde de milhões de pessoas, em especial àquelas que vivem nas proximidades dos referidos locais.

Na Região Nordeste, os dados apontam situação mais alarmante: 64,6\% dos resíduos sólidos urbanos coletados foram encaminhados, pelos municípios, para aterros controlados e lixões, enquanto apenas 35,4\% foram destinados a aterros sanitários (ASSOCIAÇÃO BRASILEIRA DE EMPRESAS DE LIMPEZA PÚBLICA E RESÍDUOS ESPECIAIS, 2017, p. 29). O Gráfico 1 abaixo propõe-se a esclarecer o destino destes resíduos, vejamos:

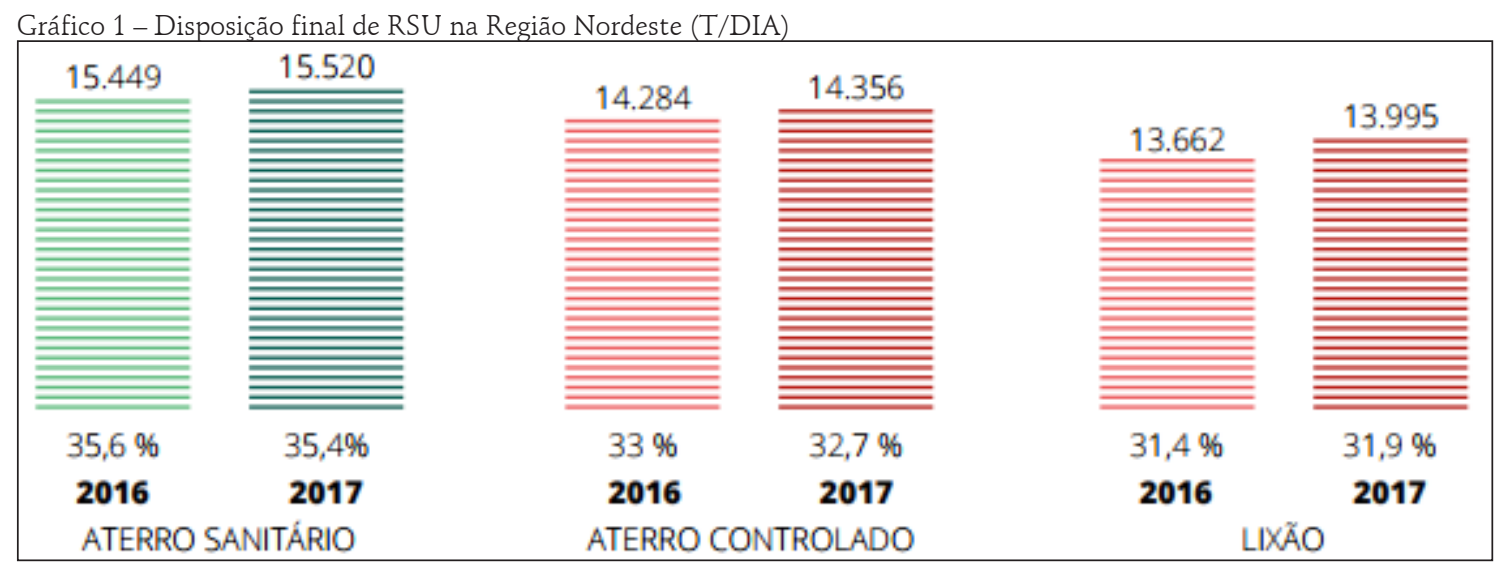

Fonte: Associação Brasileira de Empresas de Limpeza Pública e Resíduos Especiais (2017, p. 29).

Enquanto isso, a média alcançada no Brasil, para o mesmo ano, é de apenas 40,9\% de RSU dispostos em locais dessa natureza. Ademais, o Nordeste apresenta o pior índice de cobertura da coleta de RSU, calculado em 79,06\%, entre as Regiões brasileiras (ASSOCIAÇÃO BRASILEIRA DE EMPRESAS DE LIMPEZA PÚBLICA E RESÍDUOS ESPECIAIS, 2017, p. 17). Assim, os impactos 
negativos dos processos de globalização são sentidos na realidade local, haja vista o descompasso existente entre o desenvolvimento e a preservação do meio ambiente, com prejuízo para a qualidade de vida da população (RABELO, 2010).

Há que se ponderar que "[...] a concretização de uma qualidade de vida satisfatória capaz de atingir toda a sociedade está diretamente relacionada ao modo como esta sociedade dispõe da apreensão e transformação de seus recursos [...]" (FREITAS; ARAUJO; SANTOS, 2019, p. 31). O

Direito brasileiro regulamenta a etapa subsequente desse processo, por meio da Política Nacional de Resíduos Sólidos (PNRS) - Lei n. 12.305, de 2 de agosto de 2010, que estipula (sem sucesso) a obrigatoriedade de implantação da disposição final ambientalmente adequada até 2 de agosto de 2014 (BRASIL, 2010).

Os Municípios são os entes políticos responsáveis pela coleta, por determinação dos incisos I, II, V, VIII, do art. 30, da Constituição Federal de 1988. Possuem o dever constitucional de: elaborar leis sobre assuntos de interesse local; suplementar o conteúdo da legislação federal e estadual, no que for cabível; organizar e prestar os serviços públicos de interesse local, com caráter essencial, de forma direta ou mediante regime de concessão ou permissão; e, ainda, promover o adequado ordenamento do território local, por meio de planejamento e controle do uso, do parcelamento e da ocupação do solo urbano (BRASIL, 1988).

De acordo com os dados apresentados no Gráfico 1, a realidade da destinação final adequada dos resíduos sólidos, conforme previsto na PNRS, continua distante, mesmo após decorrido o prazo assinalado pelo legislador. As consequências do referido descumprimento compreendem graves danos à saúde dos indivíduos vulneráveis e ao meio ambiente, como resultado do fenômeno do racismo ambiental, na sociedade de riscos globais.

Enquanto isso, tramita no Plenário da Câmara dos Deputados o Projeto de Lei n. 2289/15, que propõe a prorrogação do prazo previsto inicialmente pela PNRS (BRASIL, 2015), para a solução do impasse em comento. A medida distancia pessoas e grupos em situação de vulnerabilidade do ideal de igualdade de dignidade defendido linhas acima.

Para realizar avanços nos padrões de vida, é preciso conceber nova estratégia de crescimento inclusivo e verde, com a garantia do compartilhamento dos benefícios do crescimento perante toda a população. Há estreita relação entre aumento da produtividade e crescimento mais inclusivo, conforme comprova a Gráfico 2: 
Gráfico 2 - Indicadores de bem-estar - Índice para uma vida melhor

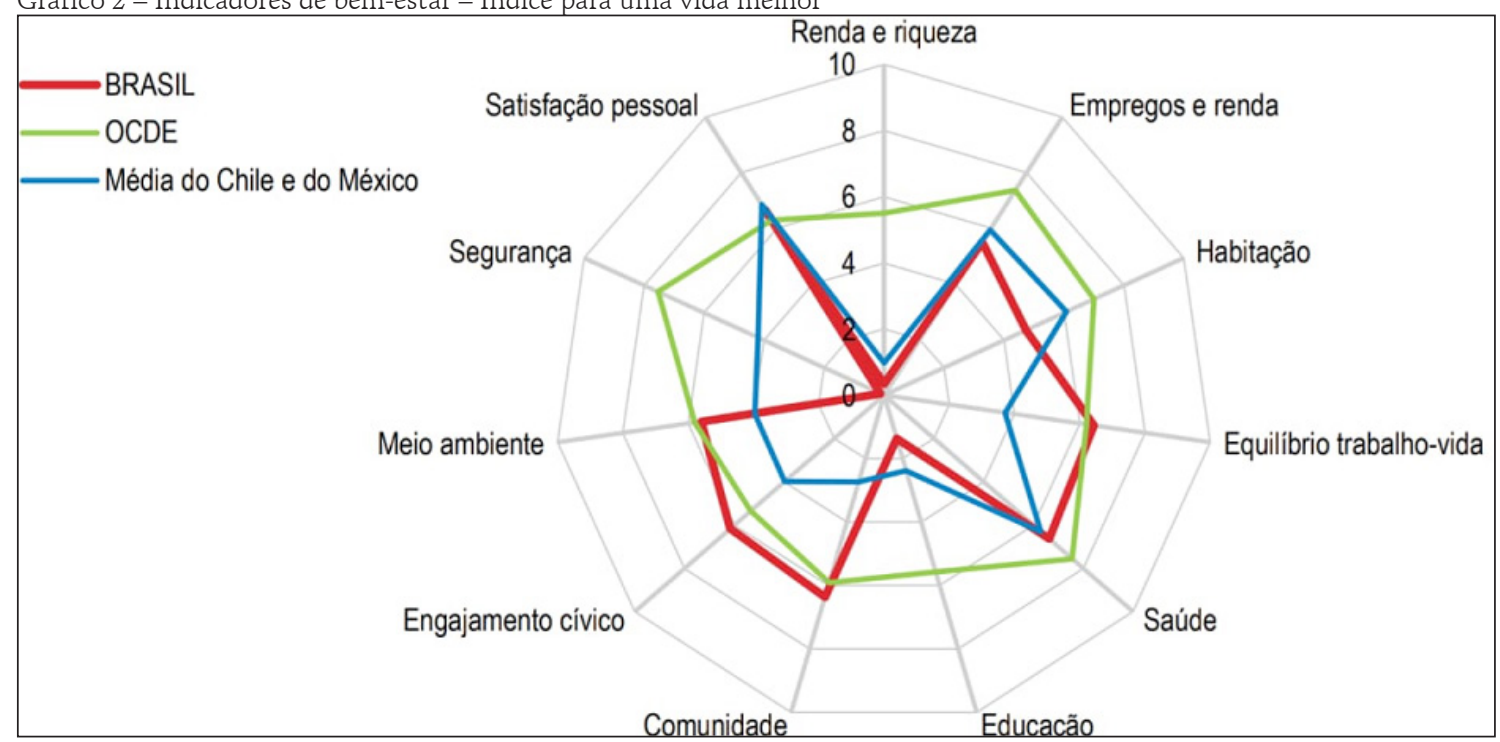

Fonte: Organização para a Cooperação e Desenvolvimento Econômico (2018b).

É nesse cenário que ganham destaque políticas públicas voltadas para o engajamento cívico, a comunidade, o meio ambiente, a satisfação social, a saúde e o equilíbrio trabalho-vida, indicadores de bem-estar mais significativos para uma vida melhor, na ótica do povo brasileiro. Este é o caso do Programa Carroceiro Legal, criado em 2017, uma política pré-aterro que propõe a redução significativa do volume de resíduos a ser encaminhado aos aterros sanitários ou nos mais de trezentos lixões existentes no Ceará. Em outubro de 2018, Fortaleza contava com cinquenta Ecopontos, locais adequados para o recebimento de pequenas proporções de entulho, restos de poda, móveis e estofados velhos, além de óleo de cozinha, papelão, plásticos, vidros e metais (FORTALEZA, 2018d).

O Programa atende ao artigo $9^{\circ}$, da Lei n. 12.305/10 (BRASIL, 2010), por privilegiar a reutilização, reciclagem, tratamento dos resíduos sólidos e disposição final ambientalmente adequada dos rejeitos. Visa ainda promover encontros educativos com os carroceiros, com o objetivo de otimizar a qualidade do vínculo entre carroceiros e Ecopontos, providenciar a eliminação de pontos de lixo e promover mudança de comportamento dos sujeitos envolvidos. A essa altura, a Prefeitura estabeleceu a meta de instalar, até 2020, um Ecoponto em cada bairro de Fortaleza, totalizando assim 119 equipamentos (FORTALEZA, 2018b).

Posteriormente, o Programa Carroceiro Legal passa a ser denominado Programa E-carroceiros, com referência aos Ecopontos e à Ecologia. Nesse formato, surge a parceria com o Banco Palmas (FORTALEZA, 2018a), que cria contas de forma gratuita para os carroceiros, nos próprios Ecopontos, com acesso a serviços como pagamento de boletos e faturas, recarga de celular, transferências, dentre outros.

O montante a ser pago é calculado por quilo de entulho direcionado aos Ecopontos, onde é realizada a pesagem em balança. Com o emprego da tecnologia, o pagamento é feito por meio de 
crédito digital na conta do carroceiro. $O$ valor recebido, por meio da moeda social E-dinheiro, pode ser utilizado no comércio credenciado na região (FORTALEZA, 2018a), de modo a promover também o desenvolvimento local. Em 2018, a ação alcançou a marca de mais de cento e sessenta carroceiros cadastrados, distribuídos pelos nove Ecopontos da Regional I e pelo Ecoponto do Jangurussu, na Regional VI (FORTALEZA, 2018e).

A Prefeitura de Fortaleza calcula que o Programa E-Carroceiros contribui para a manutenção de vários dos noventa e dois pontos de lixo eliminados por ela na área da Regional I, por meio de parceria entre a Secretaria Regional I, a Secretaria de Conservação e Serviços Públicos (SCSP), a Ecofor e o Banco Palmas (FORTALEZA, 2018c). Em suma, trata-se de política pública que envolve poder público, terceiro setor (Banco Palmas), iniciativa privada (concessionária de limpeza urbana - Ecofor Ambiental) e sociedade beneficiária (FORTALEZA, 2020).

Para participar do E-carroceiros é preciso ir a um Ecoponto, portando documento de identificação. José Eranildo Lopes, de 50 anos, foi um dos primeiros a ingressar no programa. Segundo ele: "Foi um projeto muito bom pra gente. Mudou muito a minha vida financeira e fez a gente se dedicar mais ao trabalho. Antes eu despejava lixo na rua, nas praias e agora a gente tem esse incentivo a mais. Numa média eu tiro R\$1 mil por mês agora." (FORTALEZA, 2018b). O carroceiro recomenda o programa a todos os carroceiros que conhece, no bairro Pirambu. Segundo ele, teve um aumento de $100 \%$ em sua renda, pois agora recebe pagamento do cliente e da Prefeitura. Além disso, relata sentir-se muito feliz por não jogar mais lixo no meio da rua (FORTALEZA, 2018b).

Em janeiro de 2020, a Prefeitura de Fortaleza conta com um total de 70 Ecopontos, 58,82\% da meta estabelecida em 2018 (119 equipamentos) (FORTALEZA, 2018b; 2020). Todos eles já recebem carroceiros para fins de cadastro. $O$ número de carroceiros cadastrados passou de cento e sessenta, em 2018 (FORTALEZA, 2018e), para 564 carroceiros, em 2020. Em outras palavras, mais que triplicou, no período que vai de setembro de 2018 até janeiro de 2020.

Em agosto de 2018, a adequada destinação final somava mais de 8 mil toneladas de resíduos: 7.718 toneladas de entulho de obras e 1.174 toneladas de volumosos e restos de podas, com a geração de renda de mais de $\mathrm{R} \$ 136$ mil reais durante o período de um ano (FORTALEZA, 2018c). Calcula-se que, de dezembro de 2015, data de inauguração dos equipamentos, até janeiro de 2018, já foram recolhidas mais de 139.602 toneladas de materiais. Com isso, produziu-se o benefício total de R\$1.155.121,04 em créditos digitais para os carroceiros cadastrados, por meio de cartão com moeda social, valor este a ser utilizado nos estabelecimentos comerciais de cada região (FORTALEZA, 2020).

Logo, observa-se que o Programa avançou de forma significativa, a despeito de não ter alcançado a meta de 119 equipamentos estipulada originariamente. Ademais, vislumbra-se, por meio dele, o desenvolvimento local de cada região, a partir dos créditos digitais concedidos aos E-carroceiros. Nessa linha, o programa atende ao ideal de promoção dos direitos humanos e concretiza os mandamentos contidos no artigo 4, itens 5 e 9, do Acordo de Escazú. Isto porque, verifica-se uma atuação efetiva do município de Fortaleza perante os deveres de orientação e assistência ao 
público, com atenção especial para pessoas ou grupos em situação de vulnerabilidade (os catadores). Promove, paralelamente, o uso das novas tecnologias da informação e comunicação, em parceria com o segundo e o terceiro setor, a partir de meios eletrônicos que ampliam e facilitam o acesso aos benefícios financeiros por parte dos e-carroceiros. A promoção do desenvolvimento local se dá por meio do pagamento dos catadores, realizado em dinheiro digital, que somente pode ser utilizado nos empreendimentos cadastrados no programa, situados na própria comunidade (ORGANIZAÇÃO PARA A COOPERAÇÃO E DESENVOLVIMENTO ECONÔMICO, 2018b).

Ademais, a iniciativa também se relaciona com o artigo 4, item 1, do Acordo de Escazú, que se refere ao dever das Partes de garantir ao homem o direito a viver em meio ambiente saudável, uma vez que promove a destinação final ambientalmente adequada dos resíduos transportados pelos catadores. Assim, o Programa E-carroceiros promove a inclusão social dos carroceiros e de suas famílias, favorece o desenvolvimento local dos 50 bairros em que estão situados os Ecopontos e ainda incrementa o bem-estar da população e a qualidade do meio ambiente, ao viabilizar a redução dos aterros controlados e dos lixões.

De outro giro, a iniciativa promove uma [...] conscientização do conceito de lixo e resíduo e o aprimoramento da nova visão da relevância do catador para a sociedade em geral." (FROTA et al., 2016, p. 141). Além disso, combate o descarte inadequado de resíduos mediante esforço contínuo voltado para uma parceria colaborativa entre catador, primeiro, segundo e terceiro setor. Por outro lado, conclui-se que o Programa não tem potencial para efetivar a igualdade de dignidade, haja vista a própria natureza da atividade laboral executada por estes cidadãos.

\section{Conclusão}

Os conflitos ambientais constituem efeitos perversos da globalização das atividades econômicas, em face do estoque de recursos naturais ou perante a qualidade de vida de certos grupos sociais. Contudo, o quadro conflitivo ambiental somente se configura a partir da reação dos sujeitos atingidos pelos impactos negativos do modelo capitalista globalizado vigente.

O racismo ambiental é apresentado, assim, como espécie de injustiça ambiental que transcende o aspecto cor e atinge diferentes populações economicamente vulneráveis, cujos indivíduos são tratados como não-cidadãos, seres utilizáveis e descartáveis e, até mesmo, como entrave para o desenvolvimento de projetos de interesse do Estado. Pode configurar um conflito ambiental, na hipótese de a população assimilar a consciência do problema (dano ou risco) e apresentar o desejo de mudar, por meio de mobilização organizada, com o fim de interromper ou eliminar o processo de ameaça.

Diante disso, constata-se a necessidade da promoção de ambiente saudável para o adequado desenvolvimento humano, a partir de suas capacidades, em regime de cooperação entre Estado, terceiro setor, iniciativa privada e sociedade beneficiária. Para tanto, há que se avaliar em 
que medida uma parcela da população assume os riscos da busca permanente por melhor qualidade de vida, atribuída ao grupo restrito que detém o poder econômico nos países periféricos da América Latina e do Caribe.

Isto porque, é exatamente esse modelo de organização socioeconômica hegemônica, marcado pela intensificação dos processos produtivos, massificação do consumo e progresso da ciência, que finda por promover a consolidação da sociedade de riscos globais. Cumpre ao Direito, portanto, regular tais fatos econômicos, sociais e ambientais, em prol da máxima efetivação dos direitos humanos.

As diferenças culturais podem ser expressas por meio da criação de estereótipos, capazes de fundamentar até mesmo comportamentos racistas e discriminatórios, para além de um modo de vida típico de determinado grupo social. No Brasil, a Convenção Internacional sobre a Eliminação de Todas as Formas de Discriminação Racial, promulgada pelo Decreto n. 65.810, de 8 de dezembro de 1969, já combatia todas as formas de discriminação. Da mesma forma, a despeito de não ter sido ratificada pelo Brasil, a Declaração sobre o Direito ao Desenvolvimento, de 4 de dezembro de 1986, dispõe sobre o assunto e reforça a importância dos Estados para a extinção de todas as formas de racismo e discriminação racial. Em 1993, destacam-se nesse mesmo sentido a Declaração e o Programa de Ação de Viena, atos internacionais adotados pela Conferência Mundial sobre Direitos Humanos, que atribui à eliminação do racismo e da discriminação racial a condição de objetivo prioritário da comunidade internacional e programa mundial de promoção no âmbito dos direitos humanos.

Todavia, é com o Acordo de Escazú, pactuado no cenário da América Latina e do Caribe, que ganha espaço a discussão dos direitos de acesso em questões ambientais, como medida de situar a igualdade de dignidade no centro do desenvolvimento sustentável. Constata-se que o documento promove a adoção do enfoque das capacidades, de Amartya Sen e Martha Nussbaum, no contexto interno dos Estados-nações signatários e, também, no plano internacional, o que ocasiona a substituição do enfoque da pobreza pela aferição de privações experimentadas no âmbito das capacidades mínimas do ser humano. Considera-se que a posição social é afetada por um conjunto de bens incompatíveis com renda e riqueza e que a necessidade de diferentes tipos de recursos varia segundo as pessoas e suas habilidades.

Verifica-se, portanto, que a situação das pessoas e grupos em estado de vulnerabilidade, cuja qualidade de vida é considerada baixa, mediante aferição da sua lista das capacidades, faz jus a uma persistente atenção da comunidade mundial como um todo, para além das instituições. Nessa perspectiva, os homens e mulheres - livres e capazes, aptos ao desenvolvimento de suas potencialidades, devem reconhecer a necessidade de preservar os meios de sobrevivência e de buscar o desenvolvimento humano, de forma sustentável.

Ademais, é preciso compreender a importância das normas de caráter nacional e internacional, com foco na efetivação dos direitos humanos. Diante dessa análise, e partindo da 
perspectiva da América Latina e do Caribe para a realidade local, em Fortaleza, Ceará, conclui-se que a política pública brasileira denominada Programa E-carroceiros consiste em medida de combate ao racismo ambiental, mediante a inclusão social dos carroceiros e de suas famílias, com benefícios para o desenvolvimento local dos bairros envolvidos no Programa.

Desta feita, conclui-se que o Programa, realizado por meio de parceria firmada entre Prefeitura de Fortaleza, Banco Palmas, Ecofor (iniciativa privada) e os próprios carroceiros, promove o dever de respeito e de proteção jurídica das pessoas e grupos em estado de vulnerabilidade, e, em sentido amplo, a efetivação progressiva dos direitos humanos. Nessa medida, promove a inclusão social desses trabalhadores (como resultado da reunião de esforços do Estado, iniciativa privada, terceiro setor e cidadão - em sua esfera individual e coletiva), o bem-estar da população e a qualidade do meio ambiente, por meio da redução dos aterros controlados e dos lixões.

Resta comprovado, de outro giro, que o programa pode ser classificado como uma aplicação prática, na esfera local, do que prevê o Acordo de Escazú em seu artigo 4, itens 1, 5 e 9, ratificado pelo Brasil, ainda que tal documento continue aguardando o termo inicial de sua vigência, que somente ocorrerá no nonagésimo dia contado a partir da data do depósito do décimo primeiro instrumento de ratificação, aceitação, aprovação ou adesão.

Por outro lado, o Programa não tem potencial para efetivar a igualdade de dignidade, haja vista a própria natureza da atividade laboral desempenhada pelos carroceiros envolvidos no Programa, a despeito de ter ressignificado o lixo enquanto fonte de renda para pessoas e grupos em estado de vulnerabilidade, a partir do uso de tecnologia social. Restringe-se a viabilizar a efetivação progressiva dos direitos humanos, como visto acima.

Nessa linha, as ciências sociais devem planejar e executar outras medidas, a médio e longo prazo, sob pena de correr o risco de perpetuar estratégias relevantes (como é o caso do Programa E-carroceiros) enquanto manobras ideológicas de grupos específicos, que viabilizam comportamentos discriminatórios velados. Para tanto, há que se promover mudanças estruturais correlatas, com o escopo de promover o patamar mínimo civilizatório e efetivar os direitos humanos das pessoas e grupos vulneráveis, tradicionalmente desfavorecidos. Por fim, como forma de combater esse tipo de tratamento discriminatório, conclui-se que é preciso conceber estratégias para a construção de um "governo pela sustentabilidade", nas lições de Bosselmann.

\section{Referências}

ANDRIGHETTO, Aline; OLSSON, Gustavo André. Igualdade e proteção aos direitos das minorias no Brasil. Espaço Jurídico Journal of Law, Chapecó, v. 15, n. 2, p. 443-460, jul./dez. 2014. Disponível em: http://editora.unoesc.edu.br/index.php/espacojuridico/article/view/9785/pdf. Acesso em: 15 nov. 2018. 
ASSOCIAÇÃO BRASILEIRA DE EMPRESAS DE LIMPEZA PÚBLICA E RESÍDUOS ESPECIAIS. Panorama dos Resíduos Sólidos no Brasil 2017. São Paulo, 2017. Disponível em: http://abrelpe.org.br/ download-panorama-2017. Acesso em: 9 nov. 2018.

AYALA, Patryck de Araújo. Transdisciplinaridade e os novos desafios para a proteção jurídica do ambiente nas sociedades de risco: entre direito, ciência e participação. Revista de Direito Ambiental, São Paulo, ano 16, n. 61, p. 17-36, jan./mar. 2011.

BECK, Ulrich. Sociedade de risco: rumo a uma outra modernidade. Tradução Sebastião do Nascimento. São Paulo: Editora 34, 2011.

BERCOVICI, Gilberto. O estado de exceção econômico e a periferia do capitalismo. Revista Pensar, Fortaleza, v. 11, p. 95-99, fev. 2006.

BOSSELMANN, Klaus. O princípio da sustentabilidade: transformando direito e governança. Tradução: Phillip Gil França. São Paulo: Revista dos Tribunais, 2015.

BRASIL. Câmara dos Deputados. PL n. 2289/2015. Disponível em: http://www.camara.gov.br/ proposicoesWeb/fichadetramitacao?idProposicao=1555331. Acesso em: 9 nov. 2018.

BRASIL. Constituição: República Federativa do Brasil de 1988. Brasília, DF: Senado Federal, 1988.

BRASIL. Decreto n. 65.810, de 8 de dezembro de 1969. Promulga a Convenção Internacional sobre a Eliminação de todas as Formas de Discriminação Racial. Diário Oficial da União: seção 1, Brasília, DF, p. 10536, 10 dez. 1969. Disponível em: http://www.planalto.gov.br/ccivil_03/decreto/1950-1969/D65810.html. Acesso em: 29 abr. 2020.

BRASIL. Lei n. 12.305, de 2 de agosto de 2010. Política Nacional dos Resíduos Sólidos. Institui a Política Nacional de Resíduos Sólidos; altera a Lei n. 9.605, de 12 de fevereiro de 1998; e dá outras providências. Diário Oficial da União: seção 1, Brasília, DF, p. 3, 3 ago. 2010. Disponível em: http:// www.planalto.gov.br/ccivil_03/_Ato2007-2010/2010/Lei/L12305.htm. Acesso em: 9 nov. 2018.

BRASIL. Ministério das Relações Exteriores. Assinatura do Acordo Regional sobre Acesso à Informação, Participação Pública e Acesso à Justiça em Assuntos Ambientais na América Latina e no Caribe (Acordo de Escazú). 2018. Disponível em: http://www.itamaraty.gov.br/pt-BR/notas-a-imprensa/19558-assinatura-do-acordo-regional-sobre-acesso-a-informacao-participacao-publica-e-acesso-a-justica-em-assuntos-ambientais-na-america-latina-e-no-caribe-acordo-de-escazu. Acesso em: 29 abr. 2020.

COMISSÃO ECONÔMICA PARA A AMÉRICA LATINA E O CARIBE. A América Latina e o Caribe adotam seu primeiro Acordo Regional vinculante para a proteção dos direitos de acesso em assuntos ambientais: Delegados dos países que assistiram à $9^{a}$ reunião do Comitê de Negociação sobre o Princípio 10 da Declaração do Rio aprovaram o texto final na Costa Rica. Santiago, mar. 2018a. Disponível em: https://www.cepal.org/pt-br/comunicados/america-latina-o-caribe-adotam-seu-primeiro-acordo-regional-vinculante-protecao-direitos. Acesso em: 5 nov. 2018.

COMISSÃO ECONÔMICA PARA A AMÉRICA LATINA E O CARIBE. Na sede da ONU, 14 países assinam tratado de nova geração sobre acesso à informação, participação pública e justiça em assuntos ambientais: O "Acordo de Escazú" foi aberto à assinatura dos países da América Latina e do Caribe numa cerimônia realizada no âmbito da Assembleia Geral do organismo em Nova York. Santiago, set. 2018b. Disponível em: https://www.cepal.org/pt-br/node/47243. Acesso em: 5 nov. 2018. 
COMISSÃO ECONÔMICA PARA A AMÉRICA LATINA E O CARIBE. Observatorio del Principio 10 en América Latina y el Caribe. Acuerdo Regional sobre el Acceso a la Información, la Participación Pública y el Acceso a la Justicia en Asuntos Ambientales en América Latina y el Caribe. Escazú, mar. 2020. Disponível em: https://observatoriop10.cepal.org/es/tratados/acuerdo-regional-acceso-la-informacion-la-participacion-publica-acceso-la-justicia-asuntos. Acesso em: 30 abr. 2020.

COSTA, Silvana Barros; STRAPAZZON, Carlos Luis. Teoria sobre a fundamentalidade dos direitos humanos. Cadernos de Direito, Piracicaba, v. 14, n. 27, p. 9-31, jul./dez. 2014.

FORTALEZA. Prefeitura amplia Programa que beneficia carroceiros com melhoria em renda mensal: $\bigcirc$ encontro marcará a ampliação do número de beneficiados pelo Programa, que passará de 58 para 158 carroceiros. Ago. 2018a. Disponível em: https://www.fortaleza.ce.gov.br/noticias/prefeitura-amplia-programa-que-beneficia-carroceiros-com-melhoria-em-renda-mensal. Acesso em: 30 abr. 2020.

FORTALEZA. Prefeitura de Fortaleza amplia politicas de resíduos sólidos: Novos equipamentos que estimulam o uso correto da coleta de lixo serão implementados. Aplicativo "Meu Lixo" começa a funcionar em 2019. Set. 2018b. Disponível em: https://www.fortaleza.ce.gov.br/noticias/prefeitura-de-fortaleza-amplia-politicas-de-residuos-solidos. Acesso em: 30 abr. 2020.

FORTALEZA. Prefeitura de Fortaleza amplia programa E-Carroceiro para todas as Regionais: O programa já cadastrou 564 carroceiros e gerou um benefício total de R \$ 1.155.121,04 em créditos. Jan. 2020. Disponível em: https://www.fortaleza.ce.gov.br/noticias/prefeitura-de-fortaleza-amplia-programa-e-carroceiro-para-todas-as-regionais-da-cidade. Acesso em: 30 abr. 2020.

FORTALEZA. Prefeitura de Fortaleza faz balanço de um ano de instalação de Ecopolo Leste-Oeste: Junto com o Ecopolo, surgiram os projetos inovadores Franquia Social e E-Carroceiro. Ago. 2018c. Disponível em: https://www.fortaleza.ce.gov.br/noticias/prefeitura-de-fortaleza-faz-balanco-de-um-ano-de-instalacao-do-ecopolo-leste-oeste. Acesso em: 20 out. 2019.

FORTALEZA. Prefeitura de Fortaleza inaugura $050^{\circ}$ Ecoponto da Cidade: Equipamento fica localizado no Centro e inauguração ocorre nesta sexta-feira (26/10), às 16h. Out. 2018d. Disponível em: https://www.fortaleza.ce.gov.br/noticias/prefeitura-de-fortaleza-amplia-politicas-de-residuos-solidos. Acesso em: 30 abr. 2020.

FORTALEZA. Representantes da Prefeitura do Rio de Janeiro conhecem Ecopolo da Leste-Oeste e Programa E-Carroceiro: As ações são duas condutas socioambientais exitosas implantadas pelo prefeito Roberto Cláudio há pouco mais de um ano. Set. 2018e. Disponível em: https://www.fortaleza.ce.gov.br/noticias/prefeitura-do-rio-de-janeiro-conhece-ecopolo-da-leste-oeste-e-programa-e-carroceiro. Acesso em: 20 out. 2018.

FREITAS, Ana Carla Pinheiro; ARAUJO, Liane Maria Santiago Cavalcante; SANTOS; Thiago Flores dos. Direito, desenvolvimento sustentável e a exploração energética do gás de xisto no brasil. Revista de Direito da Cidade, Rio de Janeiro, v. 11, n. 3, p. 14-38, 2019. Disponível em: https:// www.e-publicacoes.uerj.br/index.php/rdc/article/view/37691. Acesso em: 30 abr. 2020.

FROTA, Antônio Jackson Alcantara et al. Coleta seletiva: perspectivas de sustentabilidade nas associações de catadores de resíduos sólidos na cidade de Fortaleza (CE). Revista Ibero-Americana de Ciências Ambientais, Aracaju, v. 7, n. 3, p. 125-143, 2016.

NUSSBAUM, Martha. Fronteiras da Justiça: deficiência, nacionalidade, pertencimento à espécie. Tradução: Susana Castro. São Paulo: WMF: Martins Fontes, 2013. 
ORGANIZAÇÃO DAS NAÇÕES UNIDAS. Acordo Regional sobre Acesso à Informação, Participação Pública e Acesso à Justiça em Assuntos Ambientais na América Latina e no Caribe, de 4 de março de 2018. Acordo de Escazú. Escazú, 4 mar. 2018. Disponível em: https://www.cepal.org/es/ acuerdodeescazu. Acesso em: 30 abr. 2020.

ORGANIZAÇÃO DAS NAÇÕES UNIDAS. Conferência Mundial de Direitos Humanos de Viena, de 25 de junho de 1993. Declaração de Viena e Programa de Ação. Viena, 25 jun. 1993. Disponível em: https://www.ohchr.org/EN/ProfessionalInterest/Pages/Vienna.aspx. Acesso em: 29 abr. 2020.

ORGANIZAÇÃO DAS NAÇÕES UNIDAS. Resolução n. 41/128, de 4 de dezembro de 1986. Declaração sobre o direito ao desenvolvimento. Nova Iorque, 4 dez. 1986. Disponível em: http://www. direitoshumanos.usp.br/index.php/Direito-ao-Desenvolvimento/declaracao-sobre-o-direito-ao-desenvolvimento.html. Acesso em: 29 abr. 2020.

ORGANIZAÇÃO PARA A COOPERAÇÃO E DESENVOLVIMENTO ECONÔMICO. Acordo Regional de Escazú. Acordo Regional sobre Acesso à Informação, Participação Pública e Acesso à Justiça em Assuntos Ambientais na América Latina e no Caribe. Escazú, ago. 2018a. Disponível em: https://repositorio.cepal.org/bitstream/handle/11362/43611/S1800493_pt.pdf. Acesso em: 05 nov. 2018.

ORGANIZAÇÃO PARA A COOPERAÇÃO E DESENVOLVIMENTO ECONÔMICO. Relatórios Econômicos OCDE: Brasil 2018. Paris, fev. 2018b. Disponível em: https://www.oecd.org/eco/surveys/Brazil-2018-OECD-economic-survey-overview-Portuguese.pdf. Acesso em: 12 nov. 2018.

PEREIRA, Reginaldo; BROUWERS, Silvana do Prado. Sociedade de risco e racismo ambiental na globalização. Revista de Direito Ambiental, São Paulo, ano 16, n. 61, p. 37-74, jan./mar. 2011.

POMPEU, Gina Vidal Marcílio; NÉRI, Sergio. Além da sociedade de classes: a sociedade de risco e o escopo do Direito. In: ENCONTRO NACIONAL DO CONPEDI, 21., 2012, Florianopólis. Anais [...]. Florianópolis: Fundação Boiteux, 2012.

POMPEU, Gina Vidal Marcílio; SAMPAIO, Natércia. Democracia contemporânea e os critérios de justiça para o desenvolvimento socioeconômico Direito Constitucional nas relaçóes econômicas. Rio de Janeiro: Lumen Juris, 2017.

RABELO, Josinês Barbosa. Conflitos ambientais gerados pelo racismo ambiental no processo de implantação do conselho gestor da ReBio Serra Negra em terras Indígenas, PE. Cadernos de Estudos Sociais, Recife, v. 25, n. 2, p. 303-312, jul./dez. 2010.

SANTOS, Gemmelle Oliveira; SILVA, Luiz Fernando Ferreira da. Os significados do lixo para garis e catadores de Fortaleza (CE, Brasil). Revista Ciência e Saúde Coletiva, Rio de Janeiro, v. 16, n. 8, p. 3413-3419, jan./ago. 2011.

SEN, Amartya. O desenvolvimento como liberdade. Tradução: Laura Teixeira. São Paulo: Companhia das Letras, 2000.

SILVA, Rogério Luiz Nery da; HAHN, Paulo; TRAMONTINA, Roberto. Educação: direito fundamental universal. Espaço Jurídico Journal of Law [EJJL], Joaçaba: Editora Unoesc, v. 12, n. 2, p. 211-232, 2011. 